\title{
A troglobitic amphipod in the Ice Caves of the Shawangunk Ridge: Behavior and resistance to freezing
}

\author{
Luis Espinasa', Alex McCahill', Amber Kavanagh', \\ Jordi Espinasa², Alyssa M. Scott', Amy Cahill'
}

I School of Science, Marist College. Poughkeepsie, New York, USA 2 New Paltz High School. New Paltz, New York, USA

Corresponding author: Luis Espinasa (luis.espinasa@marist.edu)

Academic editor: O. Moldovan | Received 15 February 2015 | Accepted 15 April 2015 | Published 10 June 2015

http://zoobank.org/8ADC7DED-AFEB-4C3F-9991-BA360B33CE51

Citation: Espinasa L, McCahill A, Kavanagh A, Espinasa J, Scott AM, Cahill A (2015) A troglobitic amphipod in the Ice Caves of the Shawangunk Ridge: Behavior and resistance to freezing. Subterranean Biology 15: 95-104. doi: 10.3897/ subtbiol.15.4733

\begin{abstract}
Stygobromus allegheniensis Holsinger, 1967 (Allegheny Cave Amphipod) is a troglobiotic crustacean commonly found in caves of the Northeast United States. We describe several new populations from the unique tectonic Ice Caves found in the Shawangunk Ridge in New York, USA. Results also show that despite being an eyeless species, it can detect particular wavelengths of light and individuals display scotophilia, a preference for darkness. Finally, the Ice Caves pose a challenge to any aquatic troglobiont; in the winter months, the Ice Caves freeze and the floor and walls become covered in solid ice. Our results show that $S$. allegheniensis may seek warmer waters within the cave, but can also survive being frozen in solid ice.
\end{abstract}

\section{Keywords}

Stygobromus allegheniensis, amphipod, Shawangunk, scotophilia, cryoprotectant, Ice Caves, troglobite, troglobiont

\section{Introduction}

Situated atop the the Shawangunk Ridge in the mid-Hudson Valley (New York, USA) are the Ice Caves of Sam's Point, Minnewaska, and Mohonk Preserves. These caves occur at the apexes of the broad anticlinal sections of the ridge where flat-lying, truncated

Copyright Luis Espinasa et al. This is an open access article distributed under the terms of the Creative Commons Attribution License (CC BY 4.0), which permits unrestricted use, distribution, and reproduction in any medium, provided the original author and source are credited. 
beds of white Shawangunk conglomerate form cliffs. The Shawangunk Formation is a silica-cemented conglomerate of white quartz pebbles and sandstone of extreme hardness (Epstein and Epstein 1972). Unlike limestone, this type of rock does not easily undergo the chemical weathering or mechanical erosion that leads to the formation of solutional caves. On the contrary, the Ice Caves are an example of tectonic caves. When the glacial ice sheets retreated at the end of the Pleistocene about 12,000 years ago, the release of pressure from the melting of the thick overlaying ice generated a mass movement of the bedrock. The rocks separated along joints or fractures and were pulled apart mechanically. The resulting caves are usually high, narrow fissures that have nearly planar walls with matching patterns on opposite sides of the passage. The ceiling is often a flat bed of rock that did not move or that moved along a different fracture. The massively bedded, widely jointed rock at the edge of the cliff breaks up into huge blocks that tumble and lean against each other as they gradually work their way downslope.

Two circumstances potentially hinder these caves from being inhabited by troglobionts. First, tectonic caves are typically small. The longest caves described in this area are Ice Cave \#1 (138 m) at Sam's Point Preserve (Espinasa and Cahill 2011) and Xanadu Cave (422 m) at the edge of Mohonk Preserve (Millet and Boop 2013). Estimates of subterranean richness shows that larger caves accumulate species at higher rates than smaller caves (Schneider and Culver 2004). The second hindering circumstance is that snow and cold air enter the caves through the openings at the top and is then unable to escape. This refrigerated environment often preserves snow and ice into the summer. As they are aptly named, some of the Ice Caves' walls and floors are covered with solid ice, blocking many of its chambers (Fig. 1). Over the past few years in collaboration with the authorities at Sam's Point Preserve, The Nature Conservancy, and Mohonk Preserve, we have conducted studies of the fauna that inhabit the Ice Caves. The most significant discovery is that despite the aforementioned constraints, they are inhabited by an obligate cave-adapted aquatic amphipod (Westlake 2009). Specimens of these crustaceans were identified by John R. Holsinger, a taxonomic specialist of amphipods, as Stygobromus allegheniensis Holsinger, 1967, the Allegheny Cave Amphipod. This taxonomic identification has been corroborated by having identical histone sequences (GenBank\# KP696361KP696363) to specimens from Clarksville Cave, NY (Cahill et al. 2015), where S. allegheniensis has also been reported.

Stygobromus allegheniensis is fully depigmented, eyeless, and rather large, with some individuals close to $2 \mathrm{~cm}$ long (Fig. 2). The species is found in caves of Maryland, Pennsylvania, and New York. The range of this troglobiont, one of the broadest of any in the genus, covers a linear distance of approximately $596 \mathrm{~km}$ from north to south (Holsinger 1967). The species is rather common in caves developed in the glaciated Appalachian Plateau region. Despite its wide range, no significant morphological variation among populations has been found, although this may be due to the general lack of large samples that have prevented a quantitative analysis of variation (Holsinger 1967).

In the Ice Caves, during the spring, summer, and fall water seeps through cracks in the rocks and makes small streams and even pools of up to $10 \mathrm{~m}$ long and $2 \mathrm{~m}$ deep 


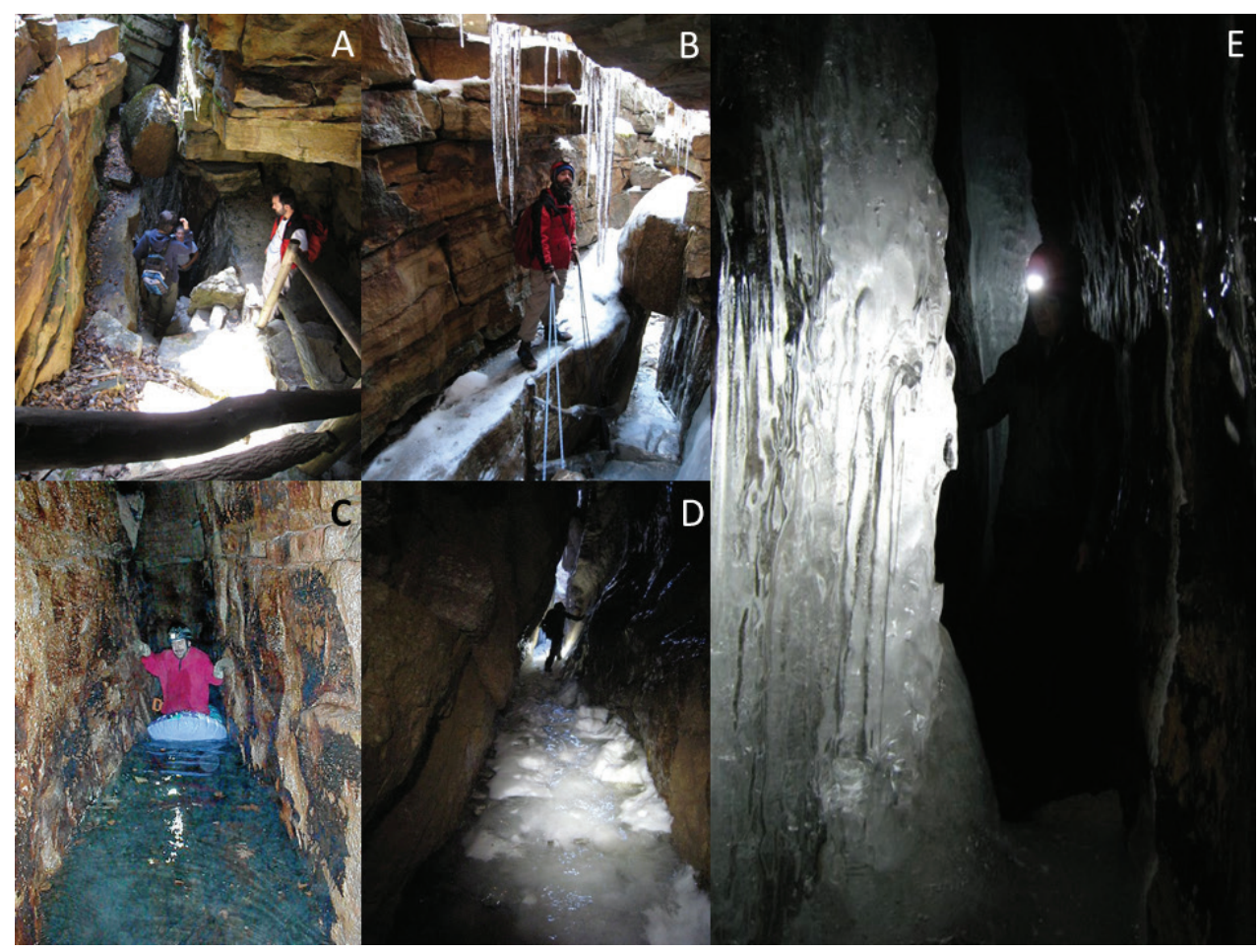

Figure I. The Ice Caves at Sam's Point Preserve, NY. Environmental conditions become challenging for the survival of aquatic troglobionts during the winter months. A-B Entrance to Ice Cave \#1 in summer (A) and winter (B) C Deep lake in Ice Cave \#2 during the Summer D Frozen floor in Ice Cave \#3 on winter E Walls in Ice Cave \#1 become covered in ice during the winter, eventually blocking the passage to its deeper chambers.

(Fig. 1C). These streams and pools are inhabited by scores of amphipods whose populations may exceed hundreds or even thousands of individuals (Espinasa and Cahill 2011). While specimens are mostly found in the dark areas of the Ice Caves, a few have been found at the entrances where light illuminates the emerging streams. The first objective of this study is to test the ability to detect light by this eyeless species. The second objective concerns an interesting phenomenon. Each winter, much of the Sam's Point caves freeze over, possibly trapping the amphipods in the ice. How can the amphipods survive this event? While the ability to survive in cold environments has been well documented for many taxa, very few cave dwelling organisms have been tested for their ability to seek warmer areas within the caves, or their ability to survive exposure to subzero temperatures (Issartel et al. 2006; Novak et al. 2014). This is probably because in typical limestone caves, temperature is for the most part constant throughout the year and extreme fluctuations in temperature are not considered one of the limiting factors influencing the life of troglobionts (Lencioni et al. 2010). Furthermore, while in the cold limestone caves in the alpine and pre-alpine regions the 


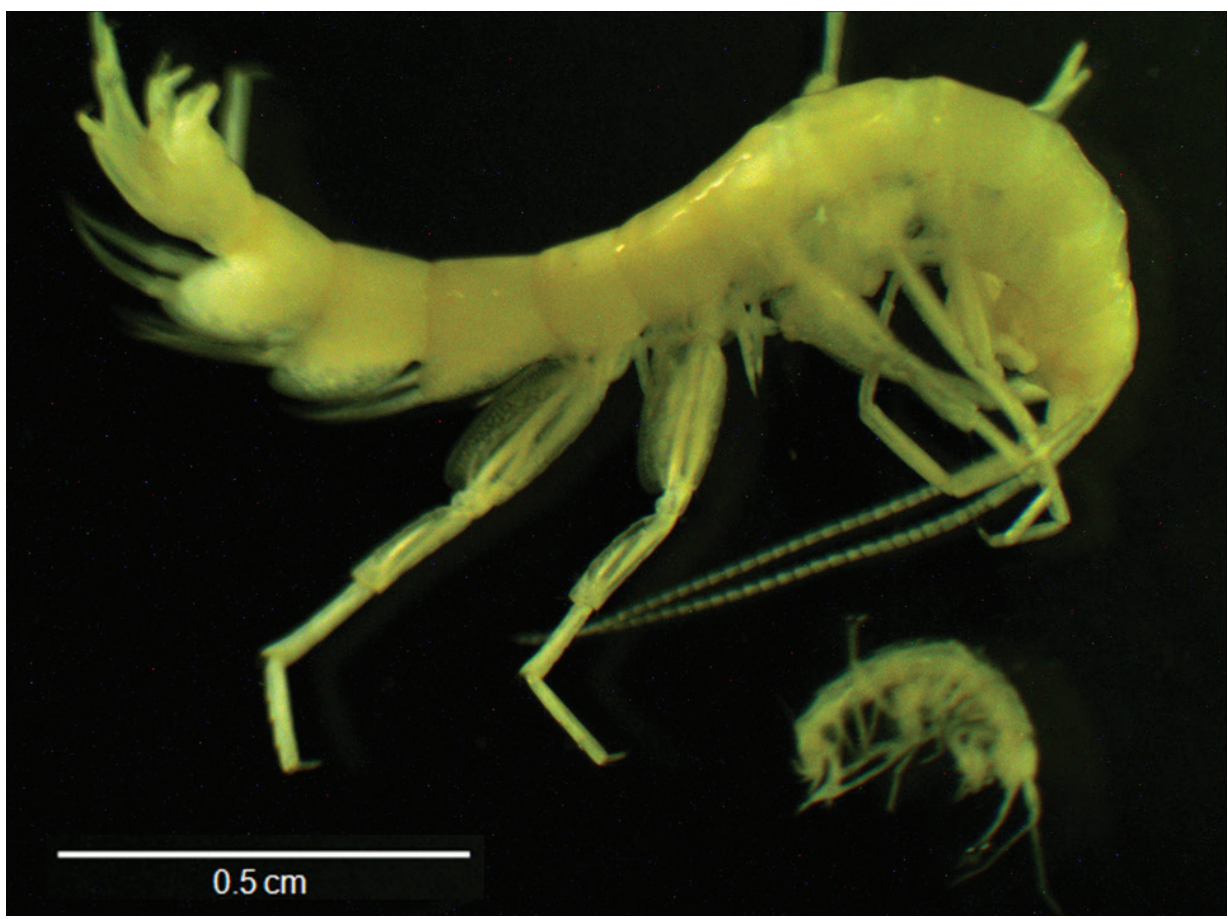

Figure 2. Adult and juvenile specimens of Stygobromus allegheniensis from Ice Cave \#1 at Sam's Point Preserve. Gravid females have been found in this cave, indicating that they are reproducing in this environment. The species is fully depigmented, eyeless, with long appendages, typical of cave-adapted organisms. During the warm months they can be found in the pools and small streams in the tectonic caves of the Shawangunk Ridge.

internal temperature is generally lower than $10{ }^{\circ} \mathrm{C}$, it rarely reaches zero or subzero temperatures (Lencioni et al. 2010). Here we present data on an aquatic troglobite that lives in tectonic caves that freeze over during winter.

\section{Methods}

Experiments were performed on 10/5/14 with $0.5-0.8 \mathrm{~cm}$ long specimens from Sam's Point Ice Cave \#1. On that date, water temperature inside the cave was $7{ }^{\circ} \mathrm{C}$. Three sets of experiments were performed: Response to light, temperature preference, and resistance to freezing. Specimens for each experiment were different and not reused.

\section{Response to light}

For the response to light, single individuals were put in a $62 \mathrm{~cm} \times 1.5 \mathrm{~cm} \times 1.5 \mathrm{~cm}$ aluminum tank whose bottom was black and filled with water from the cave. Five 
60 watt bulbs were placed $1 \mathrm{~m}$ away from the center of the tank. Half the tank was covered with black plastic so as to have two $31 \mathrm{~cm}$ long sectors; one illuminated and one dark. The specimen was left to acclimatize for $20 \mathrm{~min}$ in the tank. The time spent by the individual in the illuminated side in the next $20 \mathrm{~min}(1200 \mathrm{sec})$ was recorded. Four replicates with different individuals were performed. A two-tailed t-test was performed to establish whether there was significant difference in time spent in either side of the tank. At the end of the experiment, the temperature difference between the two sectors was recorded and found not to be significantly different (Light $=16.3{ }^{\circ} \mathrm{C}$ $+/-0.35$ Standard Deviation (SD); Dark $\left.=16.5^{\circ} \mathrm{C}+/-0.24 \mathrm{SD}\right)$. The same protocol was repeated, but instead of covering one sector with black plastic, it was covered with green, yellow, and red translucent cellophane plastics to determine if the reaction to light by these eyeless amphipods was modulated primarily by the detection of a specific color of light.

\section{Temperature preference}

For determining temperature preference, $62 \mathrm{~cm} \times 1.5 \mathrm{~cm} \times 1.5 \mathrm{~cm}$ aluminum tanks whose bottom was black and filled with water from the cave were used. A temperature gradient was made within five of these tanks by having dry ice on one end of the tanks and an electric heater pad on the other end. Amphipods could swim along the temperature gradient within the tank. Lines were drawn on top of the tanks to subdivide them into eight sectors of equal length. The first sector was completely frozen. The second had an average temperature of $2.1^{\circ} \mathrm{C}$, and the following sectors had corresponding temperatures of $7.6,11.0,14.4,17.1,20.2$ and $21.5^{\circ} \mathrm{C}(+/-0.34 \mathrm{SD})$ as recorded at the end of the experiment. One individual was deposited in each tank and left in complete darkness for $20 \mathrm{~min}$ for acclimatization. While still in complete darkness and with the help of a night vision Sony Digital 8 Handycam video camera, individual tanks were observed every two minutes and the sections where the amphipods were positioned at the end of the interval were recorded. A total of 100 data points were recorded. A Kolmogorov-Smirnov test was performed to establish whether there was significant difference in time spent in the sectors. At the end of the experiment when the lights were turned on, it was noticed that the specimen from tank \# 5 crawled out of the water, on top of the ice of sector one, and became frozen. When the ice melted some minutes later, the specimen was alive and swam around normally.

\section{Resistance to freezing}

To examine the survival capabilities of the amphipods that experience freezing, experiments were conducted in the field at Sam's Point Ice Cave \#1 and in the laboratory. In the field, individual specimens were deposited in a vial with about $5 \mathrm{ml}$ of water. The vial was then deposited in regular ice for $5 \mathrm{~min}$ and then transferred to dry ice until the 
water and specimen were frozen solid. Blocks of ice were melted after 5, 10, 15 and 60 min. The specimens in the laboratory were deposited in a $4{ }^{\circ} \mathrm{C}$ refrigerator for $24 \mathrm{hrs}$. Individuals were then transferred to vials with about $5 \mathrm{ml}$ of water and into a freezer $\left(-14^{\circ} \mathrm{C}\right)$. As soon as there was a solid block of ice, the vials were immediately transferred to $0{ }^{\circ} \mathrm{C}$ so that the specimens did not have to endure temperatures significantly lower than freezing. Blocks of ice with the amphipods were transferred to room temperature to thaw after 1,2,3 and $12 \mathrm{hrs}$ and the specimens were observed for survival.

\section{Results and discussion}

The presence of $S$. allegheniensis within the Shawangunk Ridge represents a new locality and an extension of the range for the species. Previous reports are mostly for limestone caves. Specimens of $S$. allegheniensis have been found during this study in the Ice Caves located on the eastern cliffs of Sam's Point, Ulster Co (N 41 ${ }^{\circ} 40^{\prime} 19^{\prime \prime}$, W 74²0'47" 610 masl) and at Xanadu Cave in Table Rock at the edge of Mohonk Preserve, Ulster Co (N 41 ${ }^{\circ} 48^{\prime} 55^{\prime \prime}, \mathrm{W} 74^{\circ} 06^{\prime} 45^{\prime \prime} 120$ masl). These localities are of particular interest as they show the potential of the species to form large populations within the comparatively small tectonic fissures and caves of the Shawangunk Conglomerate.

Our results also indicate that $S$. allegheniensis, despite being eyeless, detects light, and exhibits scotophilia (preference for darkness). Specimens in our experimental conditions preferred the dark side of the tanks, spending only an average of $9.9 \%$ of the time (119 seconds +/- 142 SD out of the allotted 1,200 seconds; .01>P>.005) in the illuminated side. When the black top covering half of the tank is replaced by a translucent colored cellophane filter, it was noticed that the specimens drastically change their behavior depending on the color of the light received. When the filter was yellow or red, specimens reacted in a similar way as if that half of the tank was in the dark. Out of 1,200 seconds, they spent 3.5\% (42 seconds +/- 68 SD; .001>P) and $20 \%$ (246 seconds $+/-215 \mathrm{SD} ; .05>\mathrm{P}>.02)$ in the fully illuminated side. On the contrary, when half the tank was covered by a green filter, specimens did not appear to prefer the covered side, spending $72 \%$ (874 seconds $+/-545 ; .50>\mathrm{P}>.20)$ in the fully illuminated side.

When the amphipods were presented with a temperature gradient spanning from $0-21.5^{\circ} \mathrm{C}$, all five specimens had a clear preference $(.001>\mathrm{P})$ for a temperature close to $14.4^{\circ} \mathrm{C}$ (Fig. 3). Of the seven sectors available for swimming, specimens spent $40 \%$ of the time in the sector with water at $14.4{ }^{\circ} \mathrm{C}$ followed by $25 \%$ of the time in the sector at $11.0^{\circ} \mathrm{C}$. Both temperatures are higher than the temperature of the water in the cave $\left(7^{\circ} \mathrm{C}\right)$ at the time specimens were collected. It is worth noting that while they clearly had an immediate aversion to temperatures higher than about $18.5^{\circ} \mathrm{C}$, they did not react so strongly to low temperatures (Fig. 3). Specimens were seen walking for short periods directly on the ice and one even allowed itself to be encased in the ice rather than swim to warmer water. While the event occurred at the end of the experiment, when lights were on and the observer might have been generating some noise, it is still 


\section{Temperature preference}

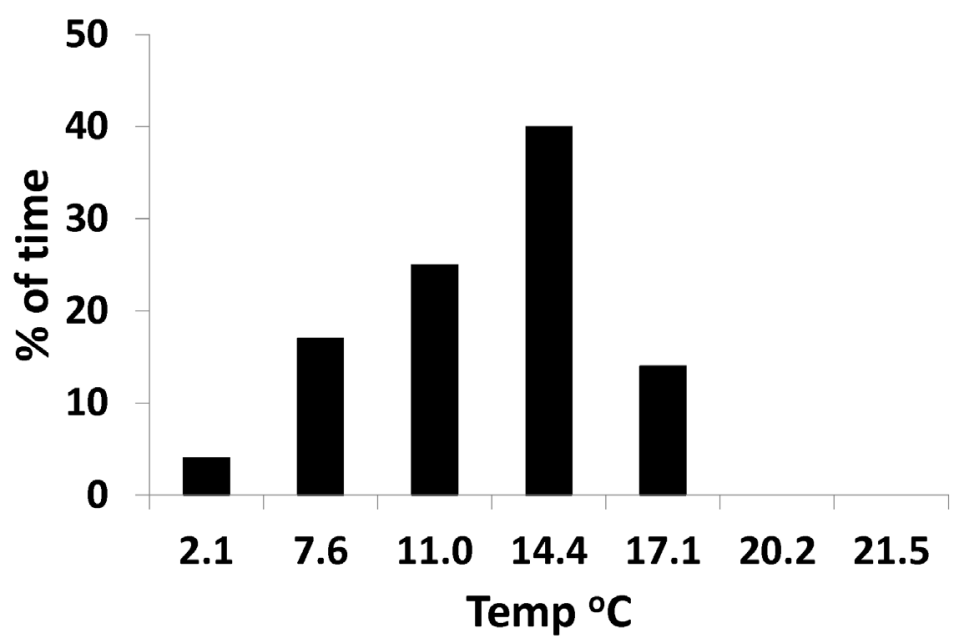

Figure 3. Temperature preference of the amphipods inhabiting Ice Cave \#1. When presented with a water temperature gradient, specimens spent most of the time swimming in water at $14.4^{\circ} \mathrm{C}$. Specimens showed a strong and immediate aversion to temperatures higher than about $18.5^{\circ} \mathrm{C}$, but not to low temperatures, with specimens walking directly on ice.

interesting that specimens would allow themselves to become encased in ice, especially considering these amphipods move quite fast even in water close to $0{ }^{\circ} \mathrm{C}$ and could have easily avoided it. When the ice was thawed, the specimen was alive and swam normally.

Specimens were frozen in the field inside a block of ice for up to $15 \mathrm{~min}$ and were still alive and moving normally when the ice was thawed. In the laboratory, where specimens were subjected to $24 \mathrm{hrs}$ at $4{ }^{\circ} \mathrm{C}$ before being frozen solid, specimens survived being frozen in a block of ice for up to $2 \mathrm{hrs}$ (Fig. 4). A movie clip of the procedure can be seen at https://www.youtube.com/watch?v=MgajTnWVl3s.

\section{Conclusions}

We report here a new series of localities where the amphipod Stygobromus allegheniensis can be found; the Ice Caves of the Shawangunk Ridge. Most previous reports for this species are from limestone caves. The new localities are from tectonic caves, which are comparatively smaller as they tend to be simple faults and cracks in the bedrock. These Ice Caves are also unique in being covered with ice even during spring. During the warmer months, some of the Ice Caves have small streams and even some $2 \mathrm{~m}$ deep pools where the amphipods can be found in great numbers.

Our results show that $S$. allegheniensis, despite being eyeless, can still detect light and shows scotophilia. Since the species can be found at the entrance of the caves, but needs to seek dark environments for its survival, it is easy to understand why this 


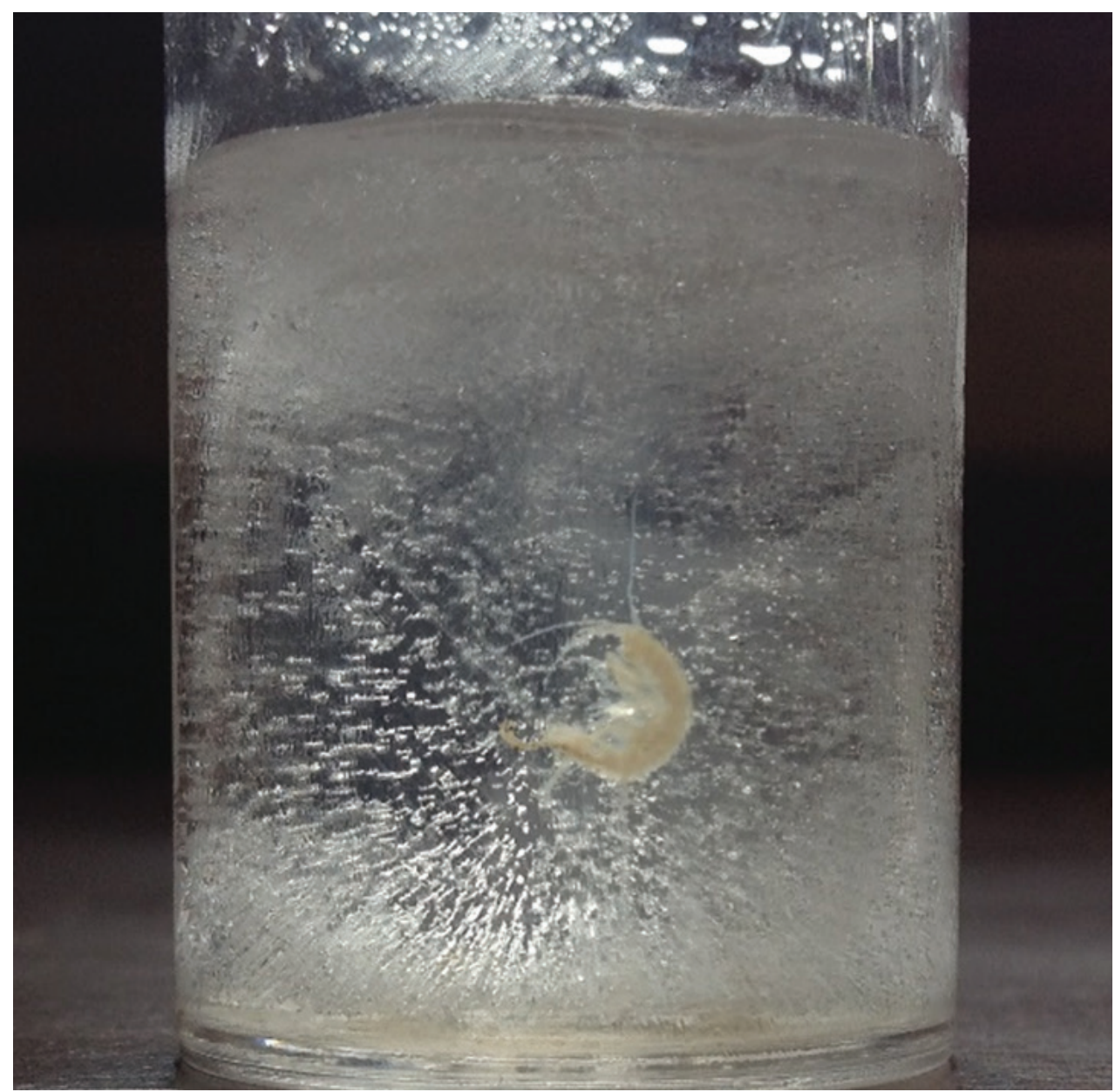

Figure 4. Specimen of S. allegheniensis frozen in a solid block of ice. Specimens were alive and behaved normally when thawed up to two hours after being frozen.

ability has been maintained. Future research should address why light detection is restricted to certain colors of light and what cells/organs are used for detection in these otherwise eyeless species.

The winter conditions of the Ice Caves pose an interesting question as to how these aquatic amphipods can survive the subzero temperatures and the coating of ice on the walls and floors of these caves. Based on our data, we propose two possible explanations. The first is that the deep pools present in the caves may not freeze entirely, just their surface, leaving a safe haven where the population can survive. As a deep pool freezes over, the amphipods would most likely remain at the bottom to avoid being frozen. Our results regarding preference for water at around $14{ }^{\circ} \mathrm{C}$ suggest that amphipods may actively move and seek the warmer, non-freezing areas. In 
the winter, ice blocking the passages that lead to these pools has prevented us from confirming this hypothesis, but should be a priority of future studies. The second explanation is that the amphipods may have the ability to survive being frozen for long periods of time in a hibernation-like state. Our results showed that amphipods can survive being frozen. Although the maximum amount of time amphipods survived in a solid block of ice in the laboratory was 2 hours, the procedure does not faithfully replicate the actual process of how the amphipods become frozen in the Ice Caves. In the field, it is most likely a progressive cooling and freezing since the temperature would show a slow decrease over weeks, allowing their metabolism to adjust accordingly. It is thus likely that in the field they are better able to survive freezing for much longer than 2 hours.

Such a process has been documented in the aquatic subterranean amphipod Niphargus rhenorhodanensis (Issartel et al. 2006). Cold acclimation induced an increase in the crystallization temperature values but no survival was observed after thawing. However, after inoculation at high sub-zero temperatures, cold-acclimated $N$. rhenorhodanensis survived. The accumulation of cryoprotective molecules such as glycerol (Issartel et al. 2006) and free amino acids (Colson-Proch 2009) may be linked to the survival of this species when this species was cold-acclimated. It may be that $S$. allegheniensis is also capable of undergoing equivalent metabolic adaptations in the cold environment encountered in the Ice Caves.

Our results already show the species can be kept alive in the laboratory for extended periods and has many interesting characteristics worthy of study. As such, it is likely that in the future the species will become a valuable model on which much more research concerning troglobites can be performed.

\section{Acknowledgments}

Partial support for the project came from the Cleveland Grotto Science Fund grant to AM and AK, from a National Speleological Society education grant to LE, and from the School of Science at Marist College. Heidi Wagner, Sam's Point Preserve Manager, was instrumental in the development of the project. Her enthusiasm, kindness, and support are greatly thanked. She even went caving to show us a cave with one of the deep pools. Collecting permits were obtained with the help of the following persons: Cara Gentry and Heidi Wagner (The Nature Conservancy, Sam's Point Preserve); John E. Thompson (Daniel Smiley Research Center, Mohonk Preserve); Laurence Davis, Thom Engel, Michael Chu, and Chuck Porter (Northeastern Cave Conservancy, Clarksville Cave Preserve). Identification of the species was performed by John R. Holsinger. Field and laboratory studies were done with the help of students from the Fall 2014 course of BIOL192: Field Biology at Marist College and Emily Collins. Finally, a thank you to Monika Espinasa for reviewing the manuscript. 


\section{References}

Cahill A, Kavanagh A, McCahill A, Scott A, Espinasa L (2015) Phylogenetic Analysis of Several New Populations of Stygobromus allegheniensis (Allegheny Cave Amphipod) in the Ice Caves of the Shawangunk Ridge, NY. The Northeast Natural History Conference, Springfield, MA.

Colson-Proch C, Renault D, Gravot A, Douady CJ, Hervant F (2009) Do current environmental conditions explain physiological and metabolic responses of subterranean crustaceans to cold? Journal of Experimental Biology 212(12): 1859-1868. doi: 10.1242/jeb.027987

Epstein JB, Epstein AG (1972) The Shawangunk Formation (upper Ordovician (?) to middle Silurian) in eastern Pennsylvania. US Government Printing Office.

Espinasa L, Cahill A (2011) Gigantism in Organisms from the Ice Caves at Sam's Point Preserve. The Northeast Natural History Conference, Albany, NY.

Holsinger JR (1967) Systematics, speciation, and distribution of the subterranean amphipod genus Stygonectes (Gammaridae). United States National Museum Bulletin 259: 1-176. doi: $10.5479 /$ si.03629236.259.1

Issartel J, Voituron Y, Odagescu V, Baudot A, Guillot G, Ruaud JP, Renault D, Vernon P, Hervant F (2006) Freezing or supercooling: how does an aquatic subterranean crustacean survive exposures at subzero temperatures? Journal of experimental biology 209(17): 3469-3475. doi: 10.1242/jeb.02387

Lencioni V, Bernabò P, Latella L (2010) Cold resistance in two species of cave-dwelling beetles (Coleoptera: Cholevidae). Journal of Thermal Biology 35(7): 354-359. doi: 10.1016/j. jtherbio.2010.07.004

Millett S, Boop L (2013) Discovery and exploration of Xanadu cave. The Underground Movement 13(10): 4-6.

Novak T, Šajna N, Antolinc E, Lipovšek S, Devetak D, Janžekovič F (2014) Cold tolerance in terrestrial invertebrates inhabiting subterranean habitats. International Journal of Speleology 43(3): 3. doi: 10.5038/1827-806X.43.3.3

Schneider K, Culver DC (2004) Estimating subterranean species richness using intensive sampling and rarefaction curves in a high density cave region in West Virginia. Journal of Cave and Karst Studies 66(2): 39-45.

Westlake T (2009) 'Jumbo' shrimp discovery: Sam's Point Ice Caves hold tiny, blind crustaceans. Shawangunk Journal 2(48): 1. 